DOI: 10.53297/18293395-2021.1-72

\title{
INVESTIGATING THE IMPACT OF AN EXTRNAL INFLUENCE ON THE DYNAMIC BEHAVIOR OF DISLOCATIONS IN SILICON CRYSTALS
}

\author{
H.R. Drmeyan ${ }^{1,2}$, V.Gh. Mirzoyan ${ }^{1}$ \\ ${ }^{I}$ Institute of Applied Problems of Physics NAS of the Republic of Armenia \\ ${ }^{2}$ Shirak State University Named after M. Nalbandyan, Gyumri, RA
}

The results of studying of the influence of a constant magnetic field on the dynamic behavior of dislocations in the crystalline block of an interferometer subsequently subjected to uniaxial mechanical tensile stress along the crystallographic axis of silicon are presented. The periodicity of the dilatation moire image after these influences, the average means free path of a dislocation in a crystal (block), the amount of slip, the average density of dislocations along the slip line, the relative deformation, and Young's modulus are calculated.

To study the effect of a stable magnetic field on the dynamic behavior of dislocations in silicon crystals, a special three-block X-ray interferometer was fabricated in one of the blocks, and dislocations were introduced using the technique proposed by us. The experiments were carried out for various values of the magnetic field induction and mechanical stress. It is shown that the sequential action of these external influences leads to an increase in the starting stress, a decrease in the velocity of dislocation movement, a delay in the onset of dislocation movement, and the appearance of a hardening phenomenon.

Experiments show that the displacement mobility characteristics are especially sensitive when the modulus of the magnetic induction vector reaches a certain threshold value for a given sample. It was shown that, in a sample containing silicon dislocations, the magnetic memory that appears after storage in a magnetic field is short-lived. It is found that the speed of movement of a dislocation in a magnetic field processed by a magnetic field, "then" subjected to mechanical stress (stretching), changes, but in practice the energy of its activation does not change. A theoretical analysis of the above experimental results is carried out, their scientific substantiation is given, all the factors associated with the phenomena observed in experiments are revealed.

Keywords: dislocation movements, magnetic treatment, drift, dislocation density, mechanical deformation.

Introduction. It is known that the field of mechanical stresses created by defects in the crystal lattice affects the physical and mechanical properties of a single crystal. In particular, the dislocation density in crystals largely determines the plasticity and strength of the material. For example, for a crystal containing dislocations, the value of the elastic modulus decreases. The reason for the decrease 
is explained in [1] and the distribution of elasticity modulus in real crystals is defined.

Additional features in the behavior of dislocations in crystals appear in the presence of a magnetic field (see [2-4]). The experiments show that the application of a magnetic field can noticeably change the plastic properties of crystals. This phenomenon is called a magnetoplastic effect. Moreover, both positive and negative magnetoplastic effects are detected, i.e. the field can cause both hardening and softening of crystals. For example, under a simultaneous influence of a weak magnetic field and constant electric current in the case of silicon crystal deformation, a significant decrease of plasticity is detected [2]. In [3], it has been shown that the dynamic deceleration of dislocations takes place in the case of their movement in the metals under the presence of a magnetic field. In [4], the deformation fields in the blocks of an X-ray interferometer under the constant magnetic field is investigated.

It is noted in [5, 6] that the constant magnetic field affects the mobility of dislocations both in metals and in silicon crystals of $\mathrm{n}$ - and p-type conductivity doped with phosphorus and boron, respectively. It is shown that under the simultaneous influence of constant electric and magnetic fields the physical-mechanical properties of these materials are changed.

In [7], the influence of the magnetic field on the dynamic behavior of the dislocations in the initial silicon crystals is studied. It was experimentally established that the action of the magnetic field itself does not lead to the dislocation movement in the initial silicon crystals. Clear changes in the dynamic behavior of dislocations were recorded only in the case when, after magnetic treatment, the mechanical deformation of the samples was carried out.

It is known [8-12] that X-ray interferometric methods are extremely sensitive to structural disturbances and have high resolution. In [8], it is shown how the theory of moire fringes on X-ray diffraction topographs of bi-crystals can be derived from the dynamic theory for reflection and transmission cases. In [9], the conditions of the formation of X-ray shift fringes are investigated aimed at applying these patterns to the study of crystal imperfections. It is theoretically provel and experimentally confirmed that the period of interference bands essentially depends on the sign of difference of interplanar spacing. [10] considers the gap width of a bicrystal in comparison with the Pendellosung length. [11] analyze the origin of the fringes based on the dynamical theory of diffraction for a distorted crystal. In the emitted beam from a lateral surface, the interference fringes were observed between the beams after different numbers of reflection in the crystal. In [12] the theory of $\mathrm{X}$-ray diffraction moire fringes with a bicrystal specimen has been described by the plane-wave dynamical diffraction theory.In the further development of the theory, 
attention was paid to the description of the double diffraction of moire interference exactly and in detail.

From the discussion above, it can be affirmed that the X-ray diffraction moire method is the only precision method that allows direct experimental studies of the stress field structure of dislocation ensembles arising in crystalline blocks of an Xray interferometer subjected to various external influences. In connection with the foregoing, it seems reasonable to study the influence of a constant magnetic field on the dynamic behavior of dislocations in silicon crystals by X-ray interferometry. The average free path of a dislocation in a crystal was chosen as an indicator and a measure of such an effect.

As for the class of simple semiconductor crystals, in particular silicon crystals, it should be noted that there is practically no literature on the study of the effect of magnetic fields on the mobility of dislocations in these crystals by X-ray interferometry. Therefore, the study of this effect by this method is certainly relevant for modern physics of semiconductors, since it brings us closer to establishing the physical mechanisms that determine the properties of plasticity and strength of semiconductor crystals.

Theoretical analysis. From the theory of moire patterns, it is known that the relative deformation $\varepsilon_{0}=\Delta d / d$ and the period $\Lambda_{D}$ of the bands of the dilated moire are related by:

$$
\varepsilon_{0}=\left|\frac{\Delta d}{d}\right|=\frac{d}{\Lambda_{D}}
$$

where $d$ is the interplanar spacing of the reflecting planes, $\Delta d$ is the absolute value of change in the interplanar spacing.

Under the action of small stresses, the dislocation segment with a length $\Delta l$ moves a small distance $L$. Due to such a small displacement an additional relative deformation occurs. This deformation is caused by dislocation deformation only. Therefore the strain values consist of elastic $\left(\varepsilon_{0}\right)$ and dislocation $\left(\varepsilon_{d}\right)$ parts:

$$
\varepsilon=\varepsilon_{0}+\varepsilon_{d}
$$

The dislocation relative deformation is determined by the expression [1]:

$$
\varepsilon_{d}=\Delta l b_{B} L \rho,
$$

where $\Delta l$ is the length of the dislocation loop, $b_{B}$ - the modulus of the Burgers vector of the dislocations, $L$ - the mean free path of the dislocation in the crystal, and $\rho$ stands for the dislocation density. Putting (3) in (2) we get:

$$
\varepsilon=\varepsilon_{0}+\Delta l b_{B} L \rho \text {. }
$$

Based on the above discussion for the period of the dilated moire pattern, we obtain [1]:

$$
\Lambda_{D}=\frac{d(1-v)}{\rho\left(\varepsilon_{0}+\Delta l \cdot b_{B} \cdot L\right)} .
$$


In [4], we have shown that the period of the dilated moire pattern obtained from a three-crystal X-ray silicon interferometer subjected to constant magnetic fields is determined by the expression:

$$
\Lambda_{D}=\frac{d(1-v)}{B\left(\mu-b_{M}\right)},
$$

where $v$ is the Poisson's ratio, $B-$ the modulus of the magnetic field induction vector, $\mu$ - the magnetic permeability of the crystal, $b_{M}$ - the constant to be determined ( $b_{M}$ expresses the increment $\mu$ along the field), it can be determined by expression [4]:

$$
\frac{\sigma}{E}=\left(\mu-b_{M}\right) \frac{B}{1-v}=\frac{d}{\Lambda_{D}}=\left|\frac{\Delta d}{d}\right| .
$$

From (5) and (6) we get;

$$
L=\frac{B\left(\mu-b_{M}\right)-\rho \varepsilon_{0}}{\rho \Delta l b_{B}} .
$$

Given (1) from (8) one obtains;

$$
L=\frac{B\left(\mu-b_{M}\right)-\rho \frac{\Delta d}{d}}{\rho \Delta l b_{B}} .
$$

As seen from (9), the mean free path of a dislocation in a crystal is inversely proportional to the dislocation density.

It is easy to determine the relationship between the mean free path of a dislocation and the shear in a crystal. Let us denote the number of effective slip planes per unit length along the normal $n_{2}$ and the number of dislocations on each of them $n_{2}$. The dislocation density in this case will be $\rho=n_{1} n_{2}$. When the dislocations move along the slip planes, individual slip packs will shift. Let $L$ be the mean free path of dislocations in a crystal. When all dislocations move in a given slip plane, the slip pack will be shifted by $\Delta l=a \mathrm{n}_{2} L, a$ being the interatomic distance. Since the thickness of the pack is equal to $\frac{1}{n_{1}}$, the magnitude of the shift in the crystal will be:

$$
\lambda=\Delta \ln _{1}=a \mathrm{n}_{1} n_{2} L=a \rho L .
$$

Experimental part. To study the effect of a constant magnetic field on the dynamic behavior of dislocations in silicon crystals, a special three-crystal interferometer was manufactured from a highly perfect single crystal of silicon (Fig. 1).

The thickness of each block of the interferometer was approximately equal to $0,8 \mathrm{~mm}$ and the $\mathrm{CuK}_{\alpha}$ radiation is used. The interferometer was made of a silicon ingot from which plates dislocation loops were not observed on the topograms. Then, 60-degree dislocations were introduced in the splitter block of the three-crystal interferometer. The source for the generation of dislocations was a scratch applied to the surface of the crystalline block. To obtain a scratch, uniform in depth (the density and distribution of generated dislocations depend on the degree of 
homogeneity), a special device was manufactured and the method proposed by us for introducing dislocations into the block of an X-ray interferometer was used [13]. After scratching, the crystal block of the interferometer was subjected to mechanical loading at $600 \ldots 700^{\circ} \mathrm{C}$ four-point bending temperature.
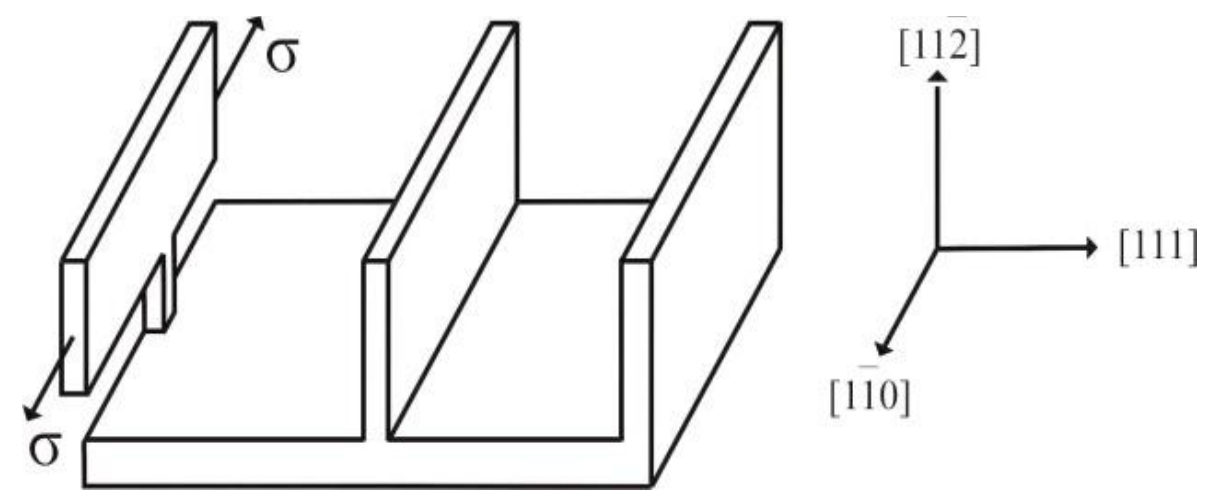

Fig. 1. A three-crystal X-ray interferometer with a selected crystallographic orientation

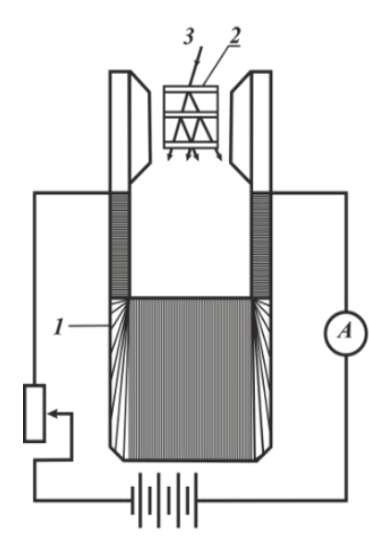

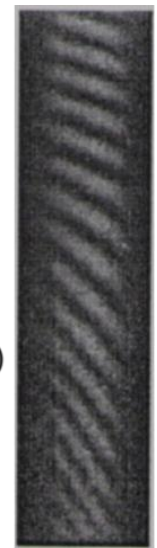

(b)

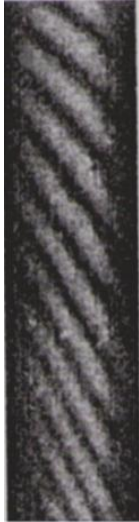

(a)

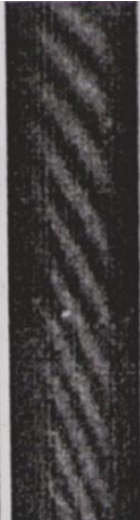

(b)

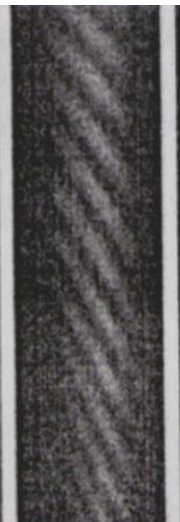

(c)

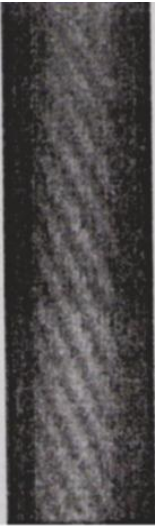

(d)

Fig. 2. $a$ - the block diagram of the experimental setup: (1) electromagnet, (2) X-ray interferometer, (3) $X$ ray beam trace; $b$ - the Moire pattern (section topographs) for

Fig. 3. Section topographs obtained from the interferometer for reflection 220 at different values of the magnetic-field strength $B: a$ $0,075, b-0,125, c-0,175$ and $d-0,225 T$ reflaction $2 \overline{2} 0$

After introducing the dislocations, the magnetic processing was carried out in the block of the interferometer: the block of the interferometer with previously introduced dislocations was placed between the poles of a specific electromagnet (Fig. 2a). In the experiment, the vector of the magnetic-field strength was directed 
perpendicular to the reflecting plans. At the beginning, when the magnetic-field strength was zero $(\mathrm{B}=0)$, the moire patterns (section topographs) from the interferometer for reflection $2 \overline{2} 0$ were recorded (Fig. $2 b$ ). The magnet was graded: the magnetic field strength was measured between the poles at different values of current passing through the magnet coil. Next, the moire patterns (section topographs) were recorded for the $2 \overline{2} 0$ reflection at values of the magnetic field strength of $\mathrm{B}=0.075,0.125,0.175$ and $0.225 \mathrm{~T}$. The resulting patterns are presented in Fig. 3. The exposure time in the magnetic field was 7 days. Next, the interferometer block splitter, which was in a magnetic field, was subjected to uniaxial mechanical tensile stress along the axis $[1 \overline{1} 0]$ (Fig. 1). The effect of the magnetic treatment on the mean free path of dislocations was studied under mechanical stress $\sigma=3,16 \cdot 10^{3} \mathrm{~Pa}$ (calculated with accuracy 0,5\%).

Experimental results and discussion. At the beginning (before the introduction of the dislocation), the moire topogram from the interferometer was taken (Fig. 4a). After introducing the dislocations in the block of the interferometer, magnetically processing it and applying mechanical stretching, the moire topogram was taken (Fig. 4b).

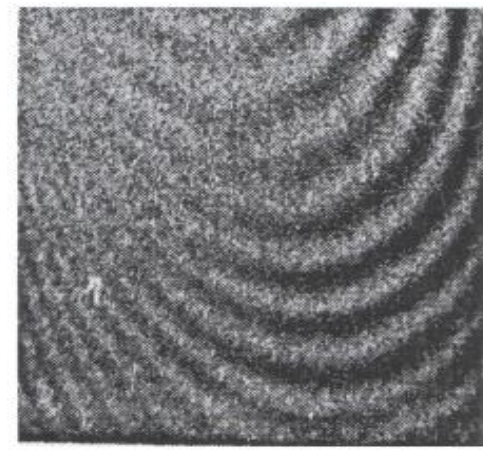

a)

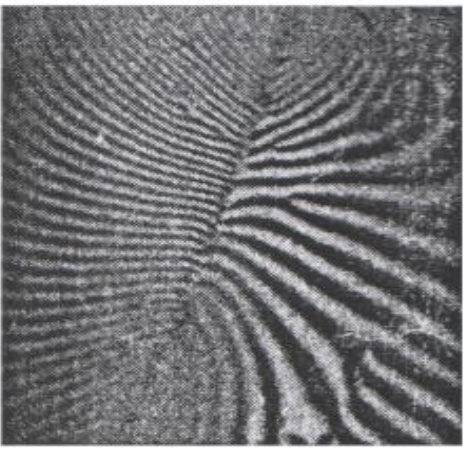

б)

Fig. 4. $a$ - the moire topogram before introducing dislocations ( $x 8) ; b$ - the moiretopogram after introducing dislocations in the block of the interferometer, its magnetic treatment and the subjectton to mechanical stretching $(x 8)$

From the measured values of the periods of the moire patterns, the absolute change in the period of the reflecting planes $(\Delta d)$ and the relative deformation $\varepsilon=$ $=\frac{\Delta d}{d}$, as well as the elastic modulus $E=\sigma / \varepsilon$ were calculated. For the relative deformation $|\Delta d / d|_{\exp } \approx 3,64 \cdot 10^{-7}$ and elastic module $E=1,672 \cdot 10^{11} \mathrm{~N} / \mathrm{m}^{2}$ was obtained. 
Further, by taking into account the fact that $\mathrm{E}_{[1 \overline{1} 0]}=1,689 \mathrm{x}$ $\times 10^{11} \mathrm{~N} / \mathrm{m}^{2}, v_{[1 \overline{1} 0]}=0,262[14], d_{(2 \overline{2} 0)}=1,92013 A^{\circ}$ (for silicon), $\mu=4 \pi \cdot 10^{-7}$ $H n / m$ the parameter $b_{M}$ at induction $B=0,075 \mathrm{~T}$ and the relative strain obtained from the experiment are estimated. For the relative strain one gets $|\Delta d / d|_{\exp } \approx$ $3,64 \cdot 10^{-7}$ and then, using (9), we obtain: $b_{M}=-2,3257 \cdot 10^{-6} \mathrm{Hn} / \mathrm{m}$.

Substituting the value $b_{M}$ in (7) and evaluating $|\Delta d / d|$ for the value of magnetic induction $B=0,125 \mathrm{~T}$, we obtain $|\Delta d / d| \approx 4,37 \cdot 10^{-7}$, that is in good agreement with our experimental result $\left(|\Delta d / d|_{\exp } \approx 4,15 \cdot 10^{-7}\right)$. Further, given that $b_{B}=2 d_{(2 \overline{2} 0)}=3,84 A^{\circ}, \Delta l=1 \mathrm{~cm}$ (from experiments), $|\Delta d / d|=|\Delta d / d|_{\exp }=$ $=4,15 \cdot 10^{-7}, \mu=4 \pi \cdot 10^{-7} \mathrm{Hn} / \mathrm{m}, B=0,17 \mathrm{~T}, b_{M}=-2,3257 \cdot 10^{-6} \mathrm{Hn} / \mathrm{m}$, for calculations, we have taken $\rho=4,02 \cdot 10^{3} \mathrm{~cm}^{-2}$. From (9) for $L$ we obtain $L \approx 2.5 \cdot 10^{-4} \mathrm{~cm}$.

The average dislocation density was determined using a metallographic microscope. So, in the center of the scratch, the dislocation density was $\rho=(1,1-1,4) \cdot 10^{6} \mathrm{cM}^{-2}$, at a distance $2 \mathrm{~mm}$ from the center $\rho=(2,1-2,4) \cdot 10^{4} \mathrm{~cm}^{-2}$ and at a distance $4 \mathrm{~mm} \rho \sim 5,6 \cdot 10^{2} \mathrm{~cm}^{-2}$. As a result for $L$ we obtain $L \approx(1.1 \div 0.39) 10^{-4} \mathrm{~cm}$.

Considering that the interatomic distance for silicon is $a=2,35 A^{\circ}$ and using expression (10), the drift value in the crystal was determined when all the dislocations were displaced in a given slip plane. For $\lambda$ we obtained $(1,1-6,1) A^{\circ}$. The results are shown in the table below.

Table

The lengths of the paths of dislocations $(L)$ and the magnitude of the shift $(\lambda)$ at different distances from the center of the $\operatorname{scratch}(X)$, the dislocation density $(\rho)$

\begin{tabular}{c|c|c|c|c|c|c|c}
\hline \multicolumn{7}{c}{ and the values of induction $(B)$} \\
\hline № & $\mathrm{B}, T$ & $\sigma, N / \mathrm{m}^{2}$ & $X, \mathrm{~mm}$ & $\rho, \mathrm{cm}^{-2}$ & $\varepsilon=\left|\frac{\Delta d}{d}\right|$ & $L, \mathrm{~cm}$ & $\lambda, A^{\circ}$ \\
\hline 1 & 0.075 & $5.3 \cdot 10^{3}$ & 0,0 & $1.25 \cdot 10^{6}$ & $3.64 \cdot 10^{-7}$ & $1.1 \cdot 10^{-4}$ & 6.13 \\
2 & 0.125 & $5.1 \cdot 10^{3}$ & 2,0 & $2.25 \cdot 10^{4}$ & $4.15 \cdot 10^{-7}$ & $2.3 \cdot 10^{-4}$ & 5.01 \\
3 & 0.175 & $4.7 \cdot 10^{3}$ & 3,0 & $4.02 \cdot 10^{3}$ & $4.41 \cdot 10^{-7}$ & $2.5 \cdot 10^{-4}$ & 3.26 \\
4 & 0.225 & $4.5 \cdot 10^{3}$ & 4,0 & $5.61 \cdot 10^{2}$ & $2.63 \cdot 10^{-7}$ & $0.39 \cdot 10^{-4}$ & 1.13 \\
\hline
\end{tabular}

The effect of the "magnetic" effect on the mobility of dislocations in diamagnetic silicon observed in the present paper can be associated with the action of a number of factors. In particular, the change in the dynamic behavior of dislocations in the initial silicon crystals as a result of their processing by magnetic 
fields can be explained by the rearrangement of the system of point defects and defect complexes that interact with the elastic fields of dislocations.

One possible explanation could be the change in the charge state of dislocations and its environment, as a result of which the Coulomb component of the interaction of dislocations with capture centers decreases and the height of the barriers that hold the dislocations at the starting positions decreases.

From our point of view, it can also be caused by the influence of additional energy, which is locally released in the dislocation region during carrier recombination in the process of mechanical deformation of the crystal. This energy facilitates the formation and movement of charged double bends at dislocations. It is likely that in our experiments the action of the magnetic field leads to a change in the polarization of the paramagnetic spin center and to a decrease in the capture probability. As a result, the probability of the carrier combination decreases.

Conclusions. The results obtained in the work made it possible to confirm that:

After holding the silicon samples in the magnetic field and with further mechanical loading, an increase in the starting stresses and a delay time of the onset of the movement of dislocations is observed, as well as a decrease in the rate of dislocation and a hardening effect is observed.

The mobility characteristics of dislocations turned out to be sensitive only to the action of a magnetic field, the induction of which reaches a certain threshold value $(B=0,17 \mathrm{~T})$.

The properties acquired as a result of magnetic treatment do not disappear immediately after the termination of the MF. The magnetic memory that appears in silicon samples with dislocations after exposure to a magnetic field is short-lived.

In silicon crystals treated with a magnetic field and subjected to mechanical stress, the speed of dislocations changes and the activation energy of their motion practically does not change.

All these experimental results still require a deeper theoretical understanding. However, now we can talk about the practical significance of the results.

Acknowledgements. This work was supported by the RA MES Science Committee, in the frames of the research project №18T-1C395. 


\section{References}

1. Drmeyan H.R .// Poverkhnost.- 2015.- N 4.- P. 24-28 (in Russian).

2. Welikhanoy A.R. // Crystallographya.- 2013.- Vol. 58, N 3.- P. 469-472 (in Russian).

3. Natsik V.D., Chishko K.A. // Crystal Res. Technol.- 1984.- Vol. 19, N 6.- P. 763.

4. Drmeyan H.R., Aboyan A.O., Movsisyan A.A. // Journal of Surface Investigation. Xray, Synchrotron and Neutron Techniques.- 2013.- Vol. 7, N 6.- P. 1056-1059.

5. Malashenko W.W. // Fiz. Nizkikh temperature.- 2008.- Vol. 34, N 9.- P. 970-974 (in Russian).

6. Welikhanov A. R.// Izv. Rass. Akad. Nauk. Serya Fiz.- 2014.- Vol. 78, N 2. -P. 176-179 (in Russian).

7. Makara V.A., et al // Westnik Kievskokogo unyversiteta. Serya Fiziko-matematicheskykh Nauk. -1999.-. N 4. -P.316 (in Russian).

8. Ohler M. and Hartwig // J ActaCryst.- 1999.- A53.- P. 413-422.

9.. Drmeyan H.R // J. ActaCryst.- 2004.- A 60.- P. 521-524,

10. Yoshimura J.// J. ActaCryst.- 1996.- A52.- P. 312-325.

11. Fukamachi, et al //J. ActaCryst.-2019.- A75.- P. 842-850.

12. Jun-ichi Yoshimura //J. ActaCryst.- 2015.- A71.- P.368-381.

13. Drmeyan H.R. Sposob generaciidislokacii v monokristalle: Certificate of Authorship No. 3222A, Republica Armenia, 2018.

14. Wordman I.J., Evans R.A. //J. Appl. Phys.-1965.-Vol. 36.- P. 153.

Received on 30.12.2020.

Accepted for publication on 21.05.2021.

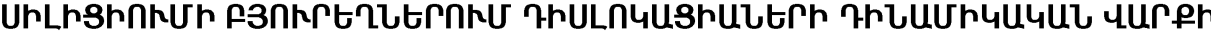

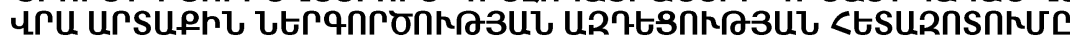

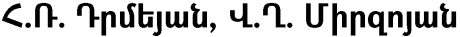

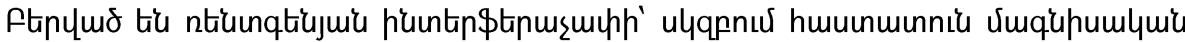

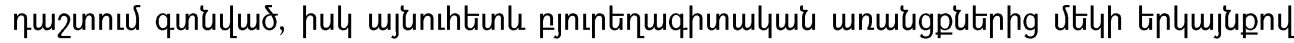

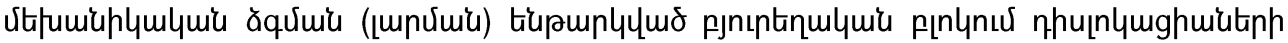

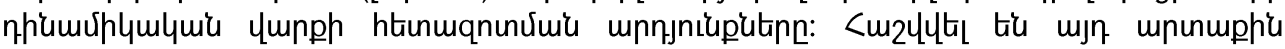

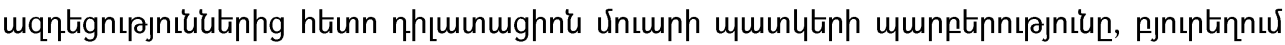

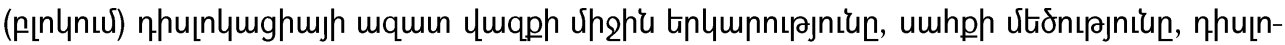

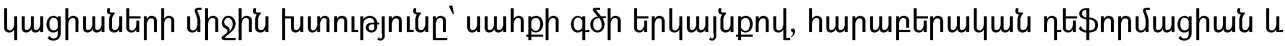
3niuqp unnnın:

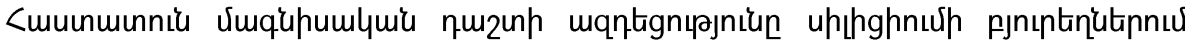

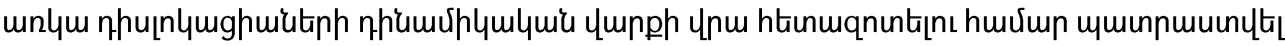

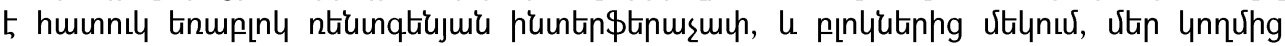
unmqunly

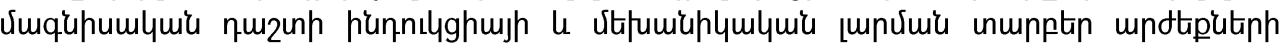

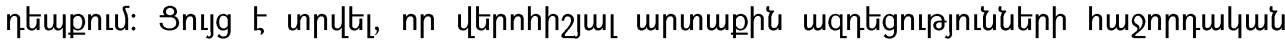

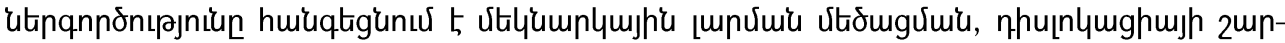

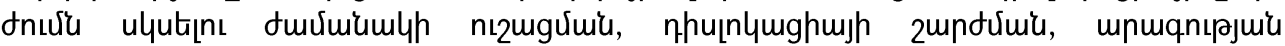

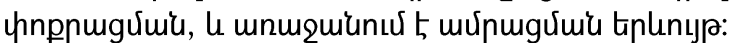

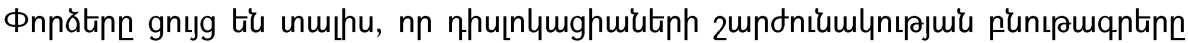

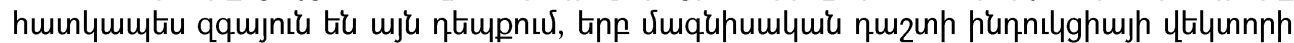




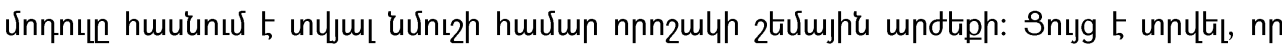

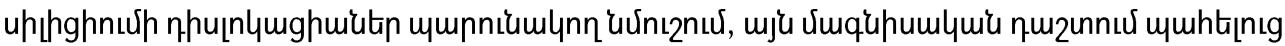

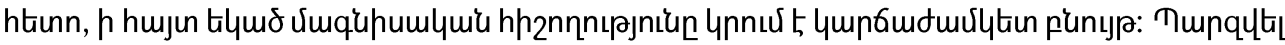

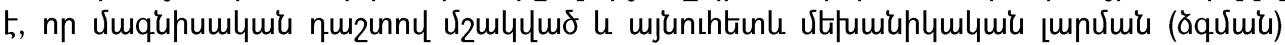

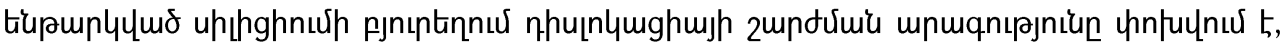

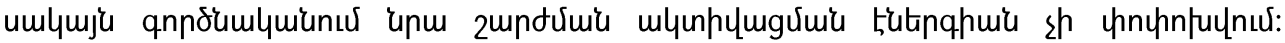

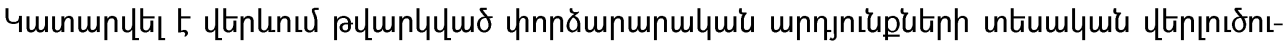

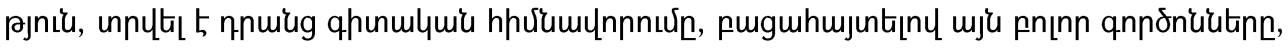

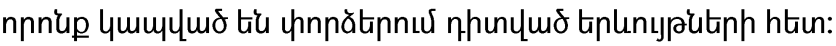

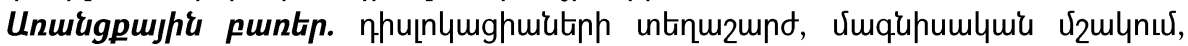

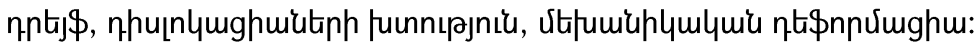

\section{ИССЛЕДОВАНИЕ ВЛИЯНИЯ ВНЕШНЕГО ВОЗДЕЙСТВИЯ НА ДИНАМИЧЕСКОЕ ПОВЕДЕНИЕ ДИСЛОКАЦИЙ В КРИСТАЛЛАХ КРЕМНИЯ}

\section{Г.Р. Дрмеян, В.К. Мирзоян}

Представлены результаты исследования динамического поведения дислокаций в кристаллическом блоке рентгеновского интерферометра, воздействия постоянного магнитного поля и затем механически растянутого напряжения вдоль одной из осей кристалла. Рассчитаны периодичность дилатационного муарового изображения после этих внешних воздействий, средняя длина свободного пробега дислокации в кристалле, величина скольжения, средняя плотность дислокаций вдоль линии скольжения, относительная деформация и модуль Юнга.

Для исследования влияния стабильного магнитного поля на динамическое поведение дислокаций в кристаллах кремния в одном из блоков был изготовлен специальный трехблочный рентгеновский интерферометр, затем по предложенной нами методике были введены дислокации. Эксперименты проводились для различных значений индукции магнитного поля и механического напряжения. Показано, что последовательное действие указанных внешних воздействий приводит к увеличению пускового напряжения, снижению скорости движения дислокации, задержке начала движения дислокации и возникновению явления упрочнения.

Эксперименты показывают, что характеристики подвижности смещения особенно чувствительны, когда модуль вектора индукции магнитного поля достигает определенного порогового значения для данного образца. Выявлено, что в образце, содержащем дислокации кремния, магнитная память, возникающая после хранения в магнитном поле, недолговечна. Обнаружено, что скорость движения дислокации в магнитном поле, обрабатываемом магнитным полем, затем подвергнутом механическому напряжению, изменяется, но на практике энергия ее активации не изменяется. Проведен теоретический анализ перечисленных выше экспериментальных результатов, дано их научное обоснование. Выявлены все факторы, связанные с наблюдаемыми в экспериментах явлениями.

Ключевые слова: перемещение дислокаций, магнитная обработка, дрейф, плотность дислокаций, механическая деформация. 